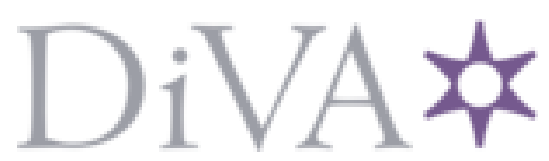

http://www.diva-portal.org

\title{
Postprint
}

This is the accepted version of a paper published in Motivation and Emotion. This paper has been peerreviewed but does not include the final publisher proof-corrections or journal pagination.

Citation for the original published paper (version of record):

Lundqvist, C., Raglin, J. (2015)

The relationship of basic need satisfaction, motivational climate and personality to well-being and stress patterns among elite athletes: An explorative study.

Motivation and Emotion, 39(2): 237-246

http://dx.doi.org/10.1007/s1 1031-014-9444-z

Access to the published version may require subscription.

N.B. When citing this work, cite the original published paper.

Permanent link to this version:

http://urn.kb.se/resolve?urn=urn:nbn:se:gih:diva-3460 
The Relationship of Basic Need Satisfaction, Motivational Climate and Personality to Well-Being and Stress Patterns among Elite Athletes: An Explorative Study

\author{
Carolina Lundqvist \\ The Swedish School of Sport and Health Sciences, Sweden \\ John S. Raglin \\ Indiana University-Bloomington, Bloomington, Indiana, USA
}

Motivation and Emotion

Doi: $10.1007 / \mathrm{s} 11031-014-9444-\mathrm{Z}$

Accepted September $20^{\text {th }} 2014$

Author Note

Acknowledgement: This study was supported by grants from the Swedish National Centre for Sports Research.

Correspondence concerning this article should be addressed to Carolina Lundqvist, The Swedish School of Sport and Health Sciences, P.O. 5626, SE-114 86 Stockholm. E-mail: carolina.lundqvist@gih.se 


\begin{abstract}
This study investigated whether need satisfaction, need dissatisfaction, motivational climate, perfectionism and self-esteem relate to athletes' discrete profiles of hedonic and eudaimonic well-being and perceived stress. Participants were 103 elite active orienteers (49 men and 54 women; mean age $=22.3 \pm 4.4$ ) who clustered into three distinctive well-being and stress patterns: Cluster 1 (lower well-being/higher stress; $n=26$ ), Cluster 2 (higher wellbeing/lower stress; $n=39$ ), and Cluster 3 (moderate well-being/moderate stress; $n=36$ ). Cluster 1 and 2 constituted distinct well-being/stress profiles and differed significantly $(p<$ $.01)$ in mastery-oriented climate, need satisfaction, need dissatisfaction, perfectionistic concerns and self-esteem scores. A discriminant analysis showed these five variables to correctly assign $88 \%$ of Cluster 1 and 2 participants into their respective groups, although masteryoriented climate was revealed as a less influential indicator (function loading $<.40$ ). The substantial function loading of need dissatisfaction supports the importance of assessing both need satisfaction and dissatisfaction as they contribute uniquely to well-being.
\end{abstract}

Keywords: positive psychology, elite orienteers, mental health, psychological functioning, emotions 
The Relationship of Basic Need Satisfaction, Motivational Climate and Personality to WellBeing and Stress Patterns among Elite Athletes: An Explorative Study

Negative experiences such as stress, injury, overtraining syndrome and illness are common in elite sport (Theberge, 2008). For example, in sports incorporating periods of intensive training, otherwise emotionally healthy athletes typically experience significant mood disturbances and in extreme cases develop clinical depression (Raglin, 2001). Notwithstanding these negative experiences, athletes also gain positive psychological, social and physical outcomes from sport participation (Harmison \& Casto, 2012) which in turn may have a beneficial impact on performance. Mental health has traditionally been studied as the absence of negative outcomes (e.g., stress or psychopathology) in various populations (cf. Kashdan, 2010; Lamers, 2012), but researchers adopting a positive psychology perspective have more recently extended the view of mental health to also include distinct indicators of well-being with the potential for increasing an individual's optimal functioning and adaptability to various stressors encountered (Keyes \& Lopez, 2009; Lamers, 2012; Lundqvist, 2011; Ryff \& Keyes, 1995). Sport psychology research on well-being has involved athletes in a number of sports, primarily at sub-elite competitive levels (cf. Lundqvist, 2011). Only one qualitative study have investigated well-being of elite athletes in the sport of orienteering, a sport that at the elite level requires high levels of aerobic condition, map reading and decision making skills. Orienteering is a global sport with a well-established world cup and annual international championships (www.orienteering.org; Lundqvist \& Sandin, in press).

\section{Hedonic and Eudaimonic Well-being}

Two philosophical views of well-being, the hedonic and eudaimonic perspective, dominate the positive psychology literature (Lundqvist, 2011; Ryan \& Deci, 2001). The hedonic perspective focuses on the emotional experience of individuals from the viewpoint that the fundamental goal of life is to achieve happiness and pleasure (Diener, 2009; Keyes \& Lopez, 
2009). Thus, well-being from this perspective is labeled as subjective or emotional well-being and is commonly evaluated based on the presence of positive affect, the absence of negative affect and the perceived life satisfaction when a person approaches valued goals and rewarding events or stimuli (Diener, 2009; Lamers, 2012). Some scholars have however argued that philosophical texts underlying the hedonic view of well-being are largely misinterpreted and criticized the perspective's weak theoretical grounding (Ryff, 1989; Ryff \& Keyes, 1995; Ryff \& Singer, 2008). The eudaimonic tradition emphasizes instead the importance of optimal functioning and flourishing in life attained by an individual's self-actualization and fulfillment of individual talents and capacities (Ryan \& Deci, 2001). Drawing from a number of theoretical perspectives (i.e., life-span developmental psychology, existential and humanistic psychology, clinical psychology), Ryff (1989; Ryff \& Keyes, 1995) developed a six dimensional model of psychological well-being which has been prominent in eudaimonic wellbeing research. The six dimensions are: (a) positive relations with others, (b) personal growth, (c) purpose in life, (d) environmental mastery, (e) self-acceptance and, (f) autonomy. Thus, psychological well-being involves psychological functioning, behaviors, needs and cognitive patterns important for long-term personal growth of the person. Although a majority of studies have relied on either the hedonic or the eudaimonic perspective, scholars have more recently proposed that the traditions should be treated as complementary perspectives because well-being involves both emotional and psychological functioning (Huta \& Ryan, 2010; Lamers, 2012; Ryan \& Deci, 2001). It also has been contended (Keyes \& Lopez, 2009) that a comprehensive conceptualization of well-being also requires assessing perceptions of illbeing, as mental health is characterized both by the presence of well-being and absence of illbeing. Perceived stress is a common symptom of a less optimal emotional and psychological functioning, expressed by negative affective states and maladaptive behavioral effects, and is known to be a common risk-factor for ill-being (Cohen \& Janicki-Deverts, 2012; Lamers, 
2012; Schinke, Battochio, Dube, Lidor, Tenenbaum, \& Lane, 2012). Thus, assessments of hedonic and eudaimonic well-being provide compatible information and perceived stress is a common life factor that may act to counterbalance individuals' evaluations of their wellbeing.

\section{Well-being Research in Competitive Sports}

Well-being from a motivational perspective. Studies of well-being in competitive athletes have largely utilized self-determination theory (SDT) in combination with the sub-theory of basic needs theory (BNT) (cf. Lundqvist, 2011; Standage, 2012). In SDT, both the content of an individual's goals and the psychological process in which goals are achieved are explained. The theory stipulates three basic needs of humans as essential for well-being; (a) competence (i.e., perception of mastery of tasks within the environment), (b) autonomy (i.e., perception of ability to make choices and decisions in the context) and, (c) relatedness (i.e., the perception of cohesion with others in the environment; Ryan \& Deci, 2000, 2001). Studies on athletes adopting SDT have generally focused on the impact of perceived autonomy support from the coach on various indicators of well-being, such as positive affect, subjective vitality or life satisfaction. The results of this work consistently reveal a positive association between the need satisfaction of athletes and their well-being (e.g., Aidie, Duda, \& Ntoumanis, 2008; Gagné, Ryan, \& Bargmann, 2003; López-Walle, Balaguer, Castillo, \& Tristán, 2012), but researchers have also proposed dissatisfaction with basic needs to be considered as satisfaction and dissatisfaction may be orthogonal (Bartholomew, Ntoumanis, Ryan, Bosch, \& Thogerson-Ntoumani, 2011; Sheldon \& Hilpert, 2012).

In studies of well-being in competitive athletes based on the achievement goal theory (AGT; Nicholls, 1992) researchers have investigated the association between a masteryoriented or performance-oriented climate and well-being (Smith, Smoll, \& Cumming, 2009; Trenz \& Zusho, 2011). A mastery- oriented climate is characterized by an emphasis on per- 
sonal improvement, cohesion and cooperation in the social context. In contrast, a performance-oriented climate is characterized by rivalry, comparisons of performance among athletes, and a focus on success and results (Harwood, Spray, \& Keegan, 2008). From the AGTperspective, research has shown a mastery-oriented climate to be associated with a large number of well-being and stress indicators and these include: Decreased performance anxiety, reduced distress toward the coach, greater perceived competence, sport satisfaction, intrinsic motivation, positive affect and basic need satisfaction (Alvarez, Balaguer, Castillo, \& Duda, 2012; Kipp \& Weiss, 2013; Pensgaard \& Roberts, 2000; Smith et al., 2009).

Well-being from a personality perspective. Some researchers have proposed that the personality constructs of self-esteem and perfectionism may be associated with various indicators of well- or ill-being, or health related behaviors (e.g., Craven \& Marsh, 2008; Lemyre, Hall, \& Roberts, 2008). Self-esteem involves an individual's self-evaluation in terms of selfworth and value (Hewitt, 2005). Research has found self-esteem to be positively associated with perceived competence in terms of realistic, intrinsically driven performance standards, satisfaction with basic psychological needs, and negatively association with depression and maladaptive perfectionism (Amarose, Anderson-Butcher, \& Cooper, 2009; Gotwals, Dunn, \& Waiment, 2003; Williams \& Galliher, 2006). Perfectionism is considered as a disposition to strive for flawless behavior or performance which sometimes includes critical self-evaluation (Stoeber, 2011). Two aspects of perfectionism have been identified: (a) Perfectionistic strivings (PS), which involves a person's tendency to set and strive to achieve high standards and, (b) perfectionistic concerns (PC) which is a maladaptive disposition toward critical selfevaluation, worry about making mistakes and negative social evaluations, and self-doubts about own capacity (Gotwals, Stoeber, Dunn, \& Stoll, 2012; Stoeber, 2011). Some research suggest that PS is positively associated with well-being variables such as positive affect and achievements or goal progress in life (cf. Gotwals et al., 2012) whereas PC is positively asso- 
ciated with ill-being including indicators such as negative affect, depression and burnout (Ashby, Noble, \& Gnilka, 2012; Hill, 2013; Hill \& Appleton, 2011). Other researchers have found that PC can act to weaken the association between PS and assessments of subjective and psychological well-being (Hill, Huelsman, \& Araujo, 2010).

\section{Rationale for the Present Study}

Sparse research in elite athletes has attempted to assess well-being from both the hedonic and eudaimonic perspectives while also accounting for the stress levels perceived. To our knowledge no study has investigated which of the various motivational (i.e., basic need satisfaction and motivational climate) and personality variables (i.e., self-esteem and perfectionism) that are the most crucial contributors to various well-being and stress profiles of elite athletes. In addition, although the relevance of need satisfaction in athletes has been established (e.g., Aidie et al., 2008; Gagné et al., 2003; López-Walle et al., 2012), the association of need dissatisfaction with well-being remains unexplored (Sheldon \& Hilpert, 2012) but researchers have argued that need satisfaction and dissatisfaction may exert independent effects. Thus, the first purpose of the present study was to investigate if elite athletes with discrete well-being/stress profiles (e.g., high well-being and low stress vs. low well-being and high stress) differ in theoretically-relevant motivational variables (i.e., need satisfaction, need dissatisfaction and motivational climate) and personality variables (i.e., perfectionism and self-esteem). Based on previous research it was anticipated that athletes with high well-being but low stress levels would score higher in measures of need satisfaction, self-esteem and perfectionistic strivings, and lower on need dissatisfaction and perfectionistic concerns compared to athletes with a pattern of lower well-being and higher stress. A second purpose was to determine the extent to which these motivational and personality variables could accurately classify athletes according to their well-being and stress profiles by means of discriminant analysis. Increased knowledge of various indicators' relative importance for athletes' well- 
and ill-being pattern, when put in comparison to each other, would help to create a more comprehensive theoretical understanding important both for future well-being research and applied work aiming to understand and ultimately predict and enhance well-being among athletes.

\section{Method}

\section{Participants}

The participants were 103 elite active orienteers ( 49 men and 54 women; mean age $=$ $22.3 \pm 4.4)$ who had practiced orienteering an average of $13.0( \pm 4.7)$ years and competed at the elite level for $5.8( \pm 3.3)$ years. All participants competed at the national elite level, and 60 of them had competed internationally over the past year on a Swedish national team. Of the sample, 46 had earned a medal at the Swedish Championships and 20 had earned a medal at the European Championships $(n=8)$ or World Championships $(n=12)$. On a self-rating scale assessing athletes personal dedication in investing time and effort to develop and to succeed in their sport, ranging from 1 (no personal investment at all in the elite sport career) to 7 (full personal investment in the elite sport career), the average elite sport dedication was $5.9( \pm$ $1.3)$.

\section{Measures}

Eight well validated psychological tools were used to assess (a) hedonic well-being, (b) eudaimonic well-being, (c) perceived stress, (d) motivational variables of motivational climate, need satisfaction and need dissatisfaction, and (e) personality factors of self-esteem and perfectionism.

Hedonic well-being. Two assessments of hedonic well-being were used: The Positive and Negative Affect Scale (PANAS; Watson, Clark, \& Tellegen, 1988) and The Satisfaction with Life Scale (SWLS; Diener, Emmons, Larsen, \& Griffin, 1985). The PANAS assesses subjective/emotional well-being in terms of the two dimensions of positive and negative af- 
fect with ten items, respectively (e.g., positive affect: "interested" and negative affect: "irritable"). Respondents are asked to rate the extent to which they have experienced each particular affective state during the past month on a five-point scale (1=very slightly/not at all to $5=$ very much; total range on each subscale: 5 to 50 ). The PANAS has revealed sound psychometric properties in non-clinical samples in terms of internal consistency, factorial validity and construct validity (Crawford \& Henry, 2004).

The SWLS (Diener et al., 1985) assesses subjective/emotional well-being in terms of the perception of respondents' life satisfaction. Respondents are asked to rate their agreement with five items (e.g., "in most ways my life is close to my ideal”) on a seven-point scale (1=strongly disagree to $7=$ strongly agree), which are summed to yield a total score that represents a perceived global satisfaction with life (total range: 5 to 35). Psychometric studies have revealed good results regarding the scale's reliability, predictive and discriminative validity and temporal stability (Pavot \& Diener, 1993).

Eudaimonic well-being. The 18-item short form of Ryff's Psychological Well-Being Scale (Ryff \& Keyes, 1995) was used which assesses self-acceptance (e.g., “When I look at the story of my life, I am pleased with how things have turned out", positive relations with others (e.g., "people would describe me as a giving person, willing to share my time with others", autonomy (e.g., "I have confidence in my opinions, even if they are contrary to the general consensus", environmental mastery (e.g., "in general, I feel I am in charge of the situation in which I live", purpose in life (e.g., "some people wander aimlessly through life, but I am not one of them") and personal growth (e.g., "I think it is important to have new experiences that challenge how you think about yourself and the world"). Each dimension is assessed using three items, and respondents rate their answers on a six-point scale $(1=$ completely disagree to $6=$ completely agree $)$. When the scale was developed, items were selected with a focus on retaining the broadness of the psychological concept partly on the 
expenses of each dimension's internal consistency (Lindfors, Berntsson, \& Lundberg, 2006; Ryff \& Keyes, 1995). Thus, in this study the recommendations by Lindfors et al. (2006) were followed and the total score of the items was computed which is an approach that has showed a sound internal consistency (total range: 18 to 108 ).

Perceived stress. The 10-item Perceived Stress Scale (PSS; Cohen, Kamarck, \& Mermelstein, 1983) was used to assess ill-being in terms of the degree of stress the respondent perceived during the previous month ( $1=$ never to $5=$ very often $)$. Each item begin with the steam: "In the last month, how often have you..." (e.g., "been upset because of something that happened unexpectedly?"). Items are summed to a total score of the perceived stress (total range: 5 to 50 ). The PSS has shown a sound internal consistency, construct and predictive validity (Cohen \& Janicki-Deverts, 2012; Cohen \& Williamson, 1988).

Motivational variables. The 18 -item Balanced Measure of Need Satisfaction Scale (BMNS; Sheldon \& Hilpert, 2012) assesses satisfaction and dissatisfaction with basic needs, including the components of autonomy, competence and relatedness. Respondents rate their answers on a five-point scale ( $1=$ no agreement to $5=$ much agreement $)$. In this study, aggregate scores of total need satisfaction (nine items; e.g. "I felt a sense of contact with people who care for me and whom I care for") and total need dissatisfaction (nine items; e.g., "I felt unappreciated by one or more important people") were computed (total range on each subscale: 5 to 45 ). The scale has revealed sound psychometric properties in terms of factorial validity, discriminant and convergent validity and predictive validity (Sheldon \& Hilpert, 2012).

The Perceived Motivational Climate in Sport Questionnaire (PMCSQ; Seifriz, Duda, \& Chi, 1992) assesses athletes' perception of their motivational climate as mastery-oriented (nine items; e.g., "the coach focuses on skill improvement") and performance-oriented (12 items; e.g., "out-playing teammates is important") using a five-point response scale 
(1=strongly disagree to $5=$ strongly agree; total range mastery subscale: 9 to 45 and total range performance subscale: 12 to 60). Psychometric studies have provided support for the scale's internal consistency, predictive and construct validity (Siefriz et al., 1992; Walling, Duda, \& Chi, 1993).

Personality variables. The Frost Multidimensional Perfectionism Scale (FMPS; Frost, Marten, Lahart, \& Rosenblate, 1990) is a 35-item index consisting of six perfectionism subscales where respondents provide their answers on a four-point response scale (1=strongly disagree to 4=strongly agree). Four of the subscales (i.e., concern over mistakes, doubts about actions, parental expectations) were summed as a total score of perfectionistic concerns (PC; total range 22 to 88; e.g., " if I do not set the highest standards for myself, I am likely to end up second-rate person"), whereas the subscales of personal standards and organization were summed as a total score of perfectionistic strivings (PS; total range 13 to 52; e.g., "organization is very important to me"). The FMPS has revealed satisfying internal consistency, factor validity and concurrent validity (Frost et al., 1990; Parker \& Adkins, 1995).

The Rosenberg Self-Esteem Scale (Rosenberg, 1965) is a ten-item scale that yields a global measure of self-esteem. Respondents rate items (e.g., "on the whole, I am satisfied with myself") on a four-point scale (1=strongly disagree to $4=$ strongly agree). The scale has revealed good psychometric properties in terms of factorial validity and internal consistency (Rosenberg, 1965; Vasconcelos-Raposo, Fernandes, Teixeira, Bertelli, 2012).

\section{Procedures}

All procedures in the study were approved by the regional ethical board (No. 2010/1660-31/5) in accordance with Swedish ethical national standards. With assistance from the Swedish Orienteering Federation (SOF), a record of all 155 elite orienteers registered with any of the Swedish national teams at a junior or senior level during the previous 12 months was compiled. Of these athletes, a total of 146 were traceable with addresses. The question- 
naires were sent to these athletes along with a letter describing the nature of the study. Instructions about how to complete the inventories were provided, including that there were no right or wrong answers to the items in the questionnaires and the importance of responding honestly, as well as information where the participants were assured confidentiality and where voluntariness of participation in the study was emphasized. Participants were also informed that returning the questionnaire implied that they provided their informed consent to participate in the study. A total of 103 athletes (71\%) returned completed questionnaires.

\section{Results}

\section{Descriptives and Data Screening}

Random single missing responses on the items constituted a total amount of .04\% of all responses and in order not to change the mean of the distribution, single missing values were replaced with mean substitution (Tabachnick \& Fidell, 2007). Data from one athlete were excluded because of multiple missing values making mean substitution inappropriate. The data were also screened for multivariate outliers (Mahalanobis distance, $p<.001$; Tabachnick $\&$ Fidell, 2007), and data from one participant were removed as a multivariate outlier $\left(\chi^{2}(3)=\right.$ $23.80, p>.001$ ) relating to the well-being and stress variables. Thus, the effective sample used in the analyses consisted of 101 athletes. Mean values, skewness, kurtosis, and internal consistency coefficients for all variables are displayed in Table 1.

\section{Cluster Analysis of Well-Being and Perceived Stress}

According to suggestions in previous hedonic well-being-research literature, an aggregate hedonic well-being score was computed for each participant by subtracting the negative affect scores from the positive affect score of the PANAS and thereafter adding the life satisfaction scores of SWLS (Diener, Suh, Lucas, \& Smith, 1999; Lucas, Diener, \& Suh, 1996). In order to group athletes in distinct profiles of their well-being and stress levels, cluster analyzes using SPSS 21 were performed. A hierarchical cluster analysis using Ward's method and 
squared Euclidean distances on $Z$-score standardized variables was first performed to determine number of well-being/stress clusters in the data (Hair, Black, Babin, Anderson, \& Tatham, 2006). The agglomeration schedule and the dendrogram indicated two or three clusters to be plausible cluster solutions. Based on the purpose of the study to use distinct clusters of athletes with higher and lower levels of well-being and stress, a three cluster solution was preferred so that athletes with moderate levels could also be identified. A K-means cluster analysis of the well-being and perceived stress variables was performed to group the athletes into the clusters, resulting in three well-being/stress patterns: Cluster $1(n=26 ; 11$ men and 15 women) possessed the lowest well-being and the highest stress scores, Cluster $2(n=39 ; 20$ men and 19 women) exhibited a pattern of highest well-being and lowest stress, and Cluster 3 ( $n=36 ; 18$ men and 18 women) was characterized by moderate levels of both well-being and stress. A substantial distance of the K-mean cluster analysis was reported between Cluster 1 and 2 (3.51), but the distances between Cluster 1 and 3 (1.72) as well as 2 and 3 (1.81) were smaller. Testing the stability of the cluster solution with discriminant analysis using the raw scores of well-being and stress showed $96 \%$ of the cross-validated grouped cases to be correctly classified, where incorrect cases referred to the moderate well-being/stress cluster (Cluster 3). Moreover, the first function separating Cluster 1 and 2 was significant (Wilk's $\Lambda=$ $\left..15, \chi^{2}(6)=183.58, p=.001\right)$ whereas function 2 was non-significant (Wilk's $\Lambda=.98, \chi^{2}(2)=$ $2.41, p=.30$ ). Thus, because the results supported that Cluster 1 and 2 constituted distinct well-being/stress profiles, whereas Cluster 3 was not distant enough from the other clusters, Cluster 1 and 2 were adopted in the further analyses. A chi-square analysis indicated that men and women were distributed equally across the clusters $\left(\chi^{2}(1)=50, p=.48\right)$. Mean values of the clusters' well-being and stress scores are shown in Table 1. A one-way MANOVA with the clusters included as fixed factors and hedonic and eudaimonic well-being and perceived stress included as dependent variables confirmed that Cluster 1 was significantly lower in 
well-being and higher in stress than Cluster 2 (main effect: Wilk's $\Lambda=.12, F(3,61)=145.48$, $p=.001$, partial $\left.\eta^{2}=.88\right)$.

\section{Multivariate Analyses of Variance}

Motivational climate and need satisfaction. To evaluate whether Cluster 1 and 2 differed in motivational constructs, a one-way MANOVA was performed with the two clusters included as fixed factors and the variables need satisfaction, need dissatisfaction, performance and mastery-oriented climate were included as dependent variables. Levine's test of equality of error variances indicated that the need satisfaction variable $(p=.01)$ was significant, and that a more conservative alpha level for this variable was necessary (Bonferroni adjustment $p$ $<.01$; Tabachnick \& Fidell, 2007). The results showed a significant main effect (Wilk's $\Lambda=$ $.39, F(4,60)=23.25, p=.001$, partial $\left.\eta^{2}=.61\right)$, and significant between subject effects where Cluster 1 displayed lower scores of need satisfaction $\left(F(1)=48.00, p=.001\right.$, partial $\eta^{2}$ $=.43)$ and mastery-oriented climate $\left(F(1)=6.43, p=.01\right.$, partial $\left.\eta^{2}=.09\right)$ but higher scores of need dissatisfaction $\left(F(1)=62.52, p=.001\right.$, partial $\left.\eta^{2}=.50\right)$ than Cluster 2. No significant between subjects effects were shown for performance-oriented climate $(F(1)=2.85, p=.10)$.

Perfectionism and self-esteem. In order to evaluate whether the clusters differed in the selected personality constructs, a one-way MANOVA was conducted with perfectionistic strivings, perfectionistic concerns and self-esteem included as dependent variables. Levine's test of equality of error variances indicated the variables of self-esteem $(F(1,63)=32.96, p=$ $.001)$ and perfectionistic strivings $(F(1,63)=7.04, p=.01)$ to be significant, and Bonferroni adjustments $p<.02$ were performed (Tabachnick \& Fidell, 2007). The results indicated a significant main effect (Wilk's $\Lambda=.41, F(3,61)=29.54, p=.001$, partial $\left.\eta^{2}=.59\right)$, and subsequent test of between effects showed that Cluster 1 displayed significant lower self-esteem ( $F$ $(1)=63.48, p=.001$, partial $\left.\eta^{2}=.50\right)$ and higher perfectionistic concerns $(F(1)=26.73, p=$ 
.001 , partial $\eta^{2}=.30$ ) than Cluster 2. No significant between subjects effects were revealed for perfectionistic strivings $(F(1)=1.05, p=.31)$.

\section{Discriminant Analysis}

Need dissatisfaction, need satisfaction, mastery-oriented climate, self-esteem and perfectionistic concerns differed significantly across Cluster 1 and 2 . These five variables were selected as independent variables in a discriminant analysis to evaluate if they correctly could be used to classify the athletes into their pre-established clusters. Prior probabilities used in the discriminant analyses were computed from group sizes of the clusters (Cluster 1: 40\%, Cluster 2: 60\%). The results showed the discriminant function to be significant (Wilk's $\Lambda=$ $\left..34, \chi^{2}(5)=65.39, p=.001\right)$ with an Eigenvalue of 1.95 and a canonical correlation of .81 . Inspecting the structure matrix revealed that self-esteem (.72) and need dissatisfaction (-.71) showed the largest loadings followed by need satisfaction (.63) and perfectionistic concerns (.47). Mastery-oriented climate revealed a discriminant loading (.23) below the cut-off value of .40 (Hair et al., 2006). The classification statistics are displayed in Table 2, and revealed that $92.3 \%$ of the originally grouped cases and $87.7 \%$ of the cross-validated cases were correctly classified by the five variables (Functions at group centroids: Cluster $1=-1.68$, Cluster $2=$ 1.12).

\section{Discussion}

The present study investigated the extent to which various motivational and personality variables were related to distinct patterns of hedonic and eudaimonic well-being and perceived stress in a sample of elite athletes. A positive psychology perspective was adopted in which mental health was considered to not only consist of absence of symptoms of a negative outcome (e.g., stress or ill-being) but also of the presence of well-being (Keyes \& Lopez, 2009; Lamers, 2012). Although the number of variables proposed in previous research to contribute to the well-being of athletes is quite large (cf. Lundqvist, 2011), the present results of 
the discriminant analysis indicate that the distinct patterns of well-being and stress levels observed in our sample could be identified with reasonable accuracy $(88 \%)$ by five variables: Need dissatisfaction, self-esteem, need satisfaction, perfectionistic concerns and masteryoriented climate. Compared to the other variables, a mastery-oriented climate had a minor function loading in the analysis, indicating that it was not a major contributor to the classification results of well-being and stress clusters in our sample of elite athletes. In addition, no significant differences between the clusters of lower well-being/higher stress and higher wellbeing/lower stress were revealed for performance-oriented climate. These results together imply that the motivational climate stipulated by the achievement goal theory (AGT) might be less crucial for the well-being/stress patterns among elite athletes than basic needs, perfectionistic concerns and self-esteem. The AGT research that has found positive correlations between motivational climate and well-being and negative correlation to anxiety has largely involved non-elite or young athletes (Alvarez et al., 2012; Reinboth \& Duda, 2006; Smith, Smoll \& Cumming, 2007). Thus, it is plausible that the motivational climate has a greater impact on younger and less experienced athletes whose primary goal is learning and improving versus elite athletes who are far more focused on competing and mastery (Keegan, Spray, Harwood, \& Lavallee, 2014). Until recently, there has been little research investigating the characteristics of a well-being promotive motivational climate among elite athletes, but recent qualitative work indicates that elite athletes may adapt to a climate more complex in nature than described by the AGT. For example, Keegan et al. (2014) found that elite athletes described a motivational climate characterized by a positive rivalry between team-mates with a focus on competition, winning and cooperation. Therefore, it is likely that elite athletes have become capable of internalizing multiple facets related to high level competition, including goals such as striving for status and comparison, and this suggests a purely dichotomous distinction between mastery or performance oriented climate to be overly simplistic in the elite context. 
Whereas the results of the present study indicate that the motivation climate from the AGT when dichotomized as mastery or performance-oriented was not substantially related to the discrete patterns of well-being and perceived stress in this sample of elite athletes, additional research is needed to determine if the results are consistent in other samples of elite athletes. In addition, further research should also explore if a well-being promotive motivational climate in the elite context displays other characteristics than exist in a non-elite context.

Need dissatisfaction was one of the most powerful indicators for the wellbeing/stress classification results in this study. The association between need satisfaction and well-being is well-established in the SDT literature (e.g., Adie et al., 2008; Gagné et al., 2003), but researchers have only recently suggested that satisfaction and dissatisfaction with basic needs exert substantially different effects on well-being (Sheldon \& Hilpert, 2012). The present results in which need dissatisfaction showed both larger effect size and function loading than need satisfaction provide some support for this latter assumption. It is plausible that dissatisfaction, in contrast to satisfaction - at least for athletes who possess fewer psychological resources - could result in negative affect and draw attention away from positive experiences and satisfaction with basic needs. Unfortunately, the pathways by which need dissatisfaction influences well-being remain unknown and few studies have assessed both basic need satisfaction/dissatisfaction and personality to study their interplay on well-being among athletes. The present results provide initial evidence that dissatisfaction is an influential variable related to the well-being/stress pattern and should therefore be explored in future research. Moreover, the results suggest need satisfaction and dissatisfaction to also interact with the personality constructs of self-esteem and perfectionism as these variables all exhibited relatively high function loadings in the cluster analysis. It is plausible that personality dispositions of self-esteem and perfectionism could act to influence how need support provided by the environment is interpreted by the athlete (Lundqvist $\&$ Sandin, in press). In the present study 
an explorative approach was adopted with a relatively small sample of Swedish elite orienteers, which did not allow for a more sophisticated analysis (e.g., structural equation modeling) of mediating or moderating variables. Additional research cross-validating the present results with larger samples of elite athletes from various sports and nationalities would add our understanding of the relationships among the investigated parameters and the generalizability of the results. Moreover, established assessments of emotional and psychological wellbeing were adopted in this study, but based on the World Health Organization (WHO; 2004) definition of mental health and suggestions by contemporary scholars within the field of positive psychology (e.g., Lamers, 2012), the construct of social well-being should also be considered.

From an applied perspective, increased knowledge about the most powerful predictors of athletes' well-being status when both well- and ill-being indicators are assessed could be useful in identifying both athletes who are likely to function well and flourish psychologically as well as those at risk of developing stress-related problems or ill-being. The present study was an initial step in the process of comparing indicators of well-being that have been proposed to be associated, but the use of a cross-sectional design precludes causal conclusions regarding the predictor variables and their influence on well-being. Prospective studies would be invaluable for determining whether the patterns of well-being and stress found in athletes evolve over the course of their careers and if so, what factors influence these changes. Reliable and valid predictors could be useful in referring at-risk athletes to counseling at an early stage before ill-being develops. Given that about $12 \%$ of the athletes in this study were incorrectly classified by the discriminant analysis, additional research is needed to identify other factors that would further enhance the accuracy of classifying athletes according to well-being patterns. For example, psychological flexibility, which includes various dynamic processes of reconfiguration of mental resources and perspective shifting, adaptation to fluctuating de- 
mands in the situation combined with a balancing of various and sometimes incongruent needs and desires in life, is one rather unexplored psychological construct that lately has been suggested as related to positive outcomes of psychological health (Kashdan, 2010). Variables theoretically linked to well-being should be investigated in order to evaluate if they increase the accuracy of predicting well-being or ill-being in athletes. Information about the most significant factors contributing to the well-being status of elite athletes, as well as the interaction between various parameters, could also be useful in designing effective well-being interventions both to prevent ill-being and to assist athletes to develop and grow psychologically in a stressful environment of elite sport. This information could have potential value for treatment modalities such as cognitive behavioral therapy (CBT) and mindfulness and acceptance interventions (MAC) that have been found to be effective in enhancing both performance related variables (e.g., flow experiences) and well-being among athletes (e.g., Gardner \& Moore, 2012; McArdle \& Moore, 2012).

In summary, in the present sample of elite athletes it was found that the level of need dissatisfaction and perfectionistic concern, combined with self-esteem and need satisfaction, are relevant indicators to elite athletes' well-being and perceived stress profiles. Although the cluster with higher well-being/lower stress also displayed a higher mastery-oriented climate than the lower well-being/higher stress cluster, motivational climate was found to be a weak indicator in comparison with other investigated variables. The results also provide support for the contention that need dissatisfaction assessed independently from need satisfaction may act to influence the well-being/stress pattern. 


\section{References}

Aidie, J.W., Duda, J.L., \& Ntoumanis, N. (2008). Autonomy support, basic need satisfaction and the optimal functioning of adult male and female sport participants: A test of basic needs theory. Motivation and Emotion, 32, 189-199. doi: 10.1007/s11031-008-9095-z

Alvarez, M.S., Balaguer, I., Castillo, I., \& Duda, J.L. (2012). The coach-created motivational climate, young athletes' well-being, and intentions to continue participation. Journal of Clinical Sport Psychology, 6, 166-179.

Amorose, A.J., Anderson-Butcher, D., \& Cooper, J. (2009). Predicting changes in athletes' well-being from changes in need satisfaction over the course of a competitive season. Research Quarterly for Exercise and Sport, 80, 386-392. doi:

10.1080/02701367.2009.10599575

Ashby, J.S., Noble, C.L., \& Gnilka, P.B. (2012). Multidimensional perfectionism, depression, and satisfaction with life: Differences among perfectionists and tests of a stressmediation model. Journal of College Counseling, 15, 130-143. doi: 10.1002/j.21611882.2012.00011.x

Bartholomew, K.J., Ntoumanis, N., Ryan, R.M., Bosch, J.A., \& Thogerson-Ntoumani, C. (2011). Self-determination theory and diminished functioning: The role of interpersonal control and psychological need thwarting. Personality and Social Psychology Bulletin, 37, 1459-1473. doi: 10.1177/0146167211413125

Cohen, S., \& Janicki-Deverts, D. (2012). Who's stressed? Distributions of psychological stress in the united states in probability samples from 1983, 2006, and 2009. Journal of Applied Social Psychology, 42, 1320-1334. doi: 10.1111/j.1559-1816.2012.00900.x

Cohen, S., Kamarck, T., \& Mermelstein, R. (1983). A global measure of perceived stress. Journal of Health and Social Behavior, 24, 386-396. doi: 10.2307/2136404 
Cohen, S., \& Williamson, G. (1988). Perceived stress in a probability sample of the United States. In S. Spacapan, \& S. Oskamp (Eds.), The social psychology of health: Claremont symposium on applied social psychology (pp. 31-67). Newbury Park, CA: Sage.

Craven, R.G., \& Marsh, H.W. (2008). The centrality of the self-concept construct for psychological wellbeing and unlocking human potential: Implications for child and educational psychologists. Educational \& Child Psychology, 25, 104-118.

Crawford, J.R., \& Henry, J.D. (2004). The Positive and Negative Affect Schedule (PANAS): Construct validity, measurement properties and normative data in a large non-clinical sample. British Journal of Clinical Psychology, 43, 245-265. doi: $10.1348 / 0144665031752934$

Diener, E. (2009). Subjective well-being. In E. Diener (Ed.), Social indicators of research series. The science of well-being (Vol. 37, pp. 11-58). New York: Springer science Business Media B.V.

Diener, E., Emmons, R.A., Larsen, R.J., \& Griffin, S. (1985). The Satisfaction With Life Scale. Journal of Personality Assessment, 49, 71-75. doi: 10.1207/s15327752jpa4901_13

Diener, E., Suh, E.M., Lucas, R.E., \& Smith, H.L. (1999). Subjective well-being: Three decades of progress. Psychological Bulletin, 125, 276-302. doi: 10.1037/00332909.125.2.276

Frost, R.O., Marten, P., Lahart, C., \& Rosenblate, R. (1990). The dimensions of perfectionism. Cognitive Therapy and Research, 14, 449-468. doi: 10.1007/BF01172967

Gagné, M., Ryan, R.M., \& Bargmann, K. (2003). Autonomy support and need satisfaction in the motivation and well-being of gymnasts. Journal of Applied Sport Psychology, 15, 372-390. doi: 10.1080/10413200390238031 
Gardner, F., \& Moore, Z. (2012). Mindfulness and acceptance models in sport psychology: A decade of basic and applied scientific advancements. Canadian Psychology, 53, 309318. doi: $10.1037 / \mathrm{a} 0030220$

Gotwals, J.K., Dunn, J.G.H., \& Waiment, H.A. (2003). An examination of perfectionism and self-esteem in intercollagiate athletes. Journal of Sport Behavior, 26, 17-38.

Gotwals, J.K., Stoeber, J., Dunn, J.G.H., \& Stoll, O. (2012). Are perfectionistic strivings in sport adaptive? A systematic review of confirmatory, contradictory, and mixed evidence. Canadian Psychology, 53, 263-279. doi: 10.1037/a0030288

Hair, J.F., Black, W.C., Babin, B.J., Anderson, R.E., \& Tatham, R.L. (2006). Multivariate data analysis $\left(6^{\text {th }}\right.$ ed.). New Jersey: Pearson Prentice Hall.

Harmison, R.J., \& Casto, K.V. (2012). Optimal performance: Elite level performance in "the zone”. In S.M. Murphy (Ed.), The Oxford handbook of sport and performance psychology (pp. 707-724). New York: Oxford University Press.

Harwood, C., Spray, C.M., Keegan, R. (2008). Achievement goal theories in sport. In T. Horn (Ed.), Advances in sport psychology ( $3^{\text {rd }}$ ed.). (pp. 131-185). Champaign IL: Human Kinetics.

Hewitt, J.P. (2005). The social construct of self-esteem. In C.R. Snyder \& S.J. Lopez (Eds.), Handbook of positive psychology (pp. 135-147). New York: Oxford University Press.

Hill, A.P. (2013). Perfectionism and burnout in junior soccer players: A test of the $2 \times 2$ model of dispositional perfectionism. Journal of Sport \& Exercise Psychology, 35, 18-29.

Hill. A.P., \& Appleton, P.R. (2011). The predictive ability of the frequency of perfectionistic cognitions, self-oriented perfectionism, and socially prescribed perfectionism in relation to symptoms of burnout in youth rugby players. Journal of Sports Sciences, 29, 695703. doi: $10.1080 / 02640414.2010 .551216$ 
Hill, R.W., Huelsman, T.J., \& Araujo, G. (2010). Perfectionistic concerns suppress associations between perfectionistic strivings and positive life outcomes. Personality and Individual Differences, 48, 584-589. doi: 10.1016/j.paid.2009.12.011

Huta, V., \& Ryan, R.M. (2010). Pursuing pleasure or virtue: The differential and overlapping well-being benefits of hedonic and eudaimonic motives. Journal of Happiness Studies, 11, 735-762. doi: 10.1007/s10902-009-9171-4

Kashdan, T.B. (2010). Psychological flexibility as a fundamental aspect of health. Clinical Psychological Review, 30, 865-878. doi:10.1016/j.cpr.2010.03.001

Keegan, R.J., Spray, C.M., Harwood, C.G., \& Lavallee, D. (2014). A qualitative investigation of the motivational climate in elite sport. Psychology of Sport and Exercise, 15, 97-107. doi: 10.1016/j.psychsport.2013.10.006

Keyes, C.L.M., \& Lopez, S.J. (2009). Toward a science of mental health. Positive directions in diagnosis and interventions. In C.R. Snyder \& S.J. Lopez (Eds.), Handbook of positive psychology (pp. 45-59). New York: Oxford University Press.

Kipp, L.E., \& Weiss, M.R. (2013). Social influences, psychological need satisfaction, and well-being among female adolescent gymnasts. Sport, Exercise, and Performance Psychology, 2, 62-75. doi: 10.1037/a0030236

Lamers, S.M.A. (2012). Positive mental health: Measurement, relevance and implications. Enschede, the Netherlands: University of Twente. doi: 10.3990/1.9789036533706 Lemyre, P.N., Hall, H.K., \& Roberts, G.C. (2008). A social cognitive approach to burnout in elite athletes. Scandinavian Journal of Medicine and Science in Sports, 18, 221-34. doi: 10.1111/j.1600-0838.2007.00671.x

Lindfors, P., Berntsson, L., \& Lundberg, U. (2006). Factor structure of Ryff's psychological well-being scales in Swedish female and male white-collar workers. Personality and Individual Differences, 40, 1213-1222. doi: 10.1016/j.paid.2005.10.016 
López-Walle, J., Balaguer, I., Castillo, I., \& Tristán, J. (2012). Autonomy support, basic psychological needs and well-being in Mexican athletes. The Spanish Journal of Psychology, 15, 1283-1292. doi: 10.5209/rev_SJOP.2012.v15.n3.39414

Lucas, R.E., Diener, E., \& Suh, E. (1996). Discriminant validity of well-being measures. Journal of Personality and Social Psychology, 71, 616-628. doi: 10.1037/00223514.71.3.616

Lundqvist, C. (2011). Well-being in competitive sports - the feel-good factor? A review of conceptual consideration of well-being. International Review of Sport and Exercise Psychology, 4, 109-127. doi: 10.1080/1750984X.2011.584067

Lundqvist, C., \& Sandin, F. (in press). Well-being in elite sport: Dimensions of hedonic and eudaimonic well-being among elite orienteers. The Sport Psychologist. doi: $10.1123 /$ tsp.2013-0024

McArdle, S., \& Moore, P. (2012). Applying evidence-based principles from CBT to sport psychology. The Sport Psychologist, 26, 299-310.

Nicholls, J.G. (1992). The general and the specific in the development and expression of achievement motivation. In G.C. Roberts (Ed.). Motivation in sport and exercise (pp. 31-56). Champaign, IL: Human Kinetics.

Parker, W.D., \& Adkins, K.K. (1995). A psychometric examination of the Multidimensional Perfectionism Scale. Journal of Psychopathology and Behavioral Assessment, 17, 323-334. doi: 10.1007/BF02229054

Pavot, W.G., \& Diener, E. (1993). Review of the Satisfaction with Life Scale. Psychological Assessment, 5, 164-172. doi: 10.1037/1040-3590.5.2.164

Pensgaard, A.M., \& Roberts, G.C. (2000). The relationship between motivational climate, perceived ability and sources of distress among elite athletes. Journal of Sport Sciences, 18, 191-200. doi: 10.1080/026404100365090 
Raglin, J.S. (2001). Psychological factors in sport performance. The Mental health model revisited. Sports Medicine, 31, 875-890. doi: 10.2165/00007256-200131120-00004

Reinboth, M., \& Duda, J.L. (2006). Perceived motivational climate, need satisfaction and indices of well-being in team sports: A longitudinal perspective. Psychology of Sport and Exercise, 7, 269-286. doi:10.1016/j.psychsport.2005.06.002

Rosenberg, M. (1965). Society and the adolescent self-image. Princeton, NJ: Princeton University Press.

Ryan, R.M., \& Deci, E.L. (2001). On happiness and human potentials: A review of research on hedonic and eudaimonic well-being. Annual Review of Psychology, 52, 141-166. doi: 10.1146/annurev.psych.52.1.141

Ryan, R.M., \& Deci, E.L. (2002). An overview of self-determination theory. In E.L. Deci \& R.M. Ryan (Eds.), Handbook of self-determination research (pp. 3-33). Rochester, NY: University of Rochester Press.

Ryff, C.D. (1989). Happiness is everything, or is it? Exploration on the meaning of psychological well-being. Journal of Personality and Social Psychology, 57, 1069-1081. doi: $10.1037 / 0022-3514.57 .6 .1069$

Ryff, C.D. (2013). Eudaimonic well-being and health: Mapping consequences of selfrealization. In A.S. Waterman (Ed.), The best within us: Positive psychology perspectives on eudaimonia (pp. 77-98). Washington, Dc: American Psychological Association.

Ryff, C.D., \& Keyes, C.L.M. (1995). The structure of psychological well-being revisited. Journal of Personality and Social Psychology, 69, 719-727. doi: 10.1037/00223514.69.4.719 
Ryff, C.D., \& Singer, B.H. (2008). Know thyself and become what you are. A eudaimonic approach to psychological well-being. Journal of Happiness Studies, 9, 13-39. Doi: $10.007 / \mathrm{s} 10902-006-9019-0$

Schinke, R.J., Battochio, R.C., Dube, T.V., Lidor, R., Tenenbaum, G., \& Lane, A.M. (2012). Adaptation processers affecting performance in elite sports. Journal of Clinical Sport Psychology, 6, 180-185.

Seifriz, J.J., Duda, J.L., \& Chi, L. (1992). The relationship of perceived motivational climate to intrinsic motivation and beliefs about success in basketball. Journal of Sport \& Exercise Psychology, 14, 375-391.

Sheldon, K.M., \& Hilpert, J.C. (2012). The balanced measure of psychological needs (BMPN) scale: An alternative domain general measure of need satisfaction. Motivation and Emotion, 36, 439-451. doi 10.1007/s11031-012-9279-4

Smith, R.E., Smoll, F.L., \& Cumming, S.P. (2007). Effects of a motivational climate intervention for coaches on young athletes' sport performance anxiety. Journal of Sport \& Exercise Psychology, 29, 39-59. doi:

Smith, R.E., Smoll, F.L., \& Cumming, S.P. (2009). Motivational climate and changes in young athletes' achievement goal orientation. Motivation and Emotion, 33, 173-183. doi: 10.1007/s11031-009-9126-4

Standage, M. (2012). Motivation: Self-determination theory and performance in sport. In S.M. Murphy (Ed.), The Oxford handbook of sport and performance psychology (pp. 233-249). New York: Oxford University Press.

Stoeber, J. (2011). The dual nature of perfectionism in sports: Relationships with emotion, motivation, and performance. International Review of Sport and Exercise Psychology, 4, 128-145. doi: 10.1080/1750984X.2011.604789 
Tabachnick, B.G., \& Fidell, L.S. (2007). Using multivariate statistics (5th ed.). Needham Heights, MA: Allyn \& Bacon.

Theberge, N. (2008). "Just a normal bad part of what I do": Elite athletes accounts of the relationship between health and sport. Sociology of Sport Journal, 25, 206-222.

Trenz, R.C., \& Zusho, A. (2011). Competitive swimmers' perception of motivational climate and their personal achievement goals. International Journal of Sports Science \& Coaching, 6 , 433-443. doi: 10.1260/1747-9541.6.3.433

Vasconcelos-Raposo, J., Fernandes, H.M., Teixeira, C.M., \& Bertelli, R. (2012). Factorial validity and invariance of the Rosenberg Self-Esteem Scale among Portuguese youngsters. Social Indicators Research, 105, 483-498. doi: 10.1007/s11205-011-9782-0

Walling, M.D., Duda, J.L., \& Chi, L. (1993). The Perceived Motivational Climate in Sport Questionnaire: Construct and predictive validity. Journal of Sport \& Exercise Psychology, 15, 172-183.

Watson, D., Clark, L.A., \& Tellegen, A. (1988). Development and validation of a brief measure of positive and negative affect: The PANAS Scales. Journal of Personality and Social Psychology, 54, 1063-1070. doi: 10.1037/0022-3514.54.6.1063

Williams, K.L., \& Galliher, R.V. (2006). Predicting depression and self-esteem from social connectedness, support, and competence. Journal of Social and Clinical Psycholology, 25, 855-874. doi: 10.1521/jscp.2006.25.8.855

World Health Organization (2004). Promoting mental health: Concepts, emerging evidence, practice. Geneva: WHO. 
Table 1

Descriptives of Assessed Variables in the Three Clusters and the Total Sample

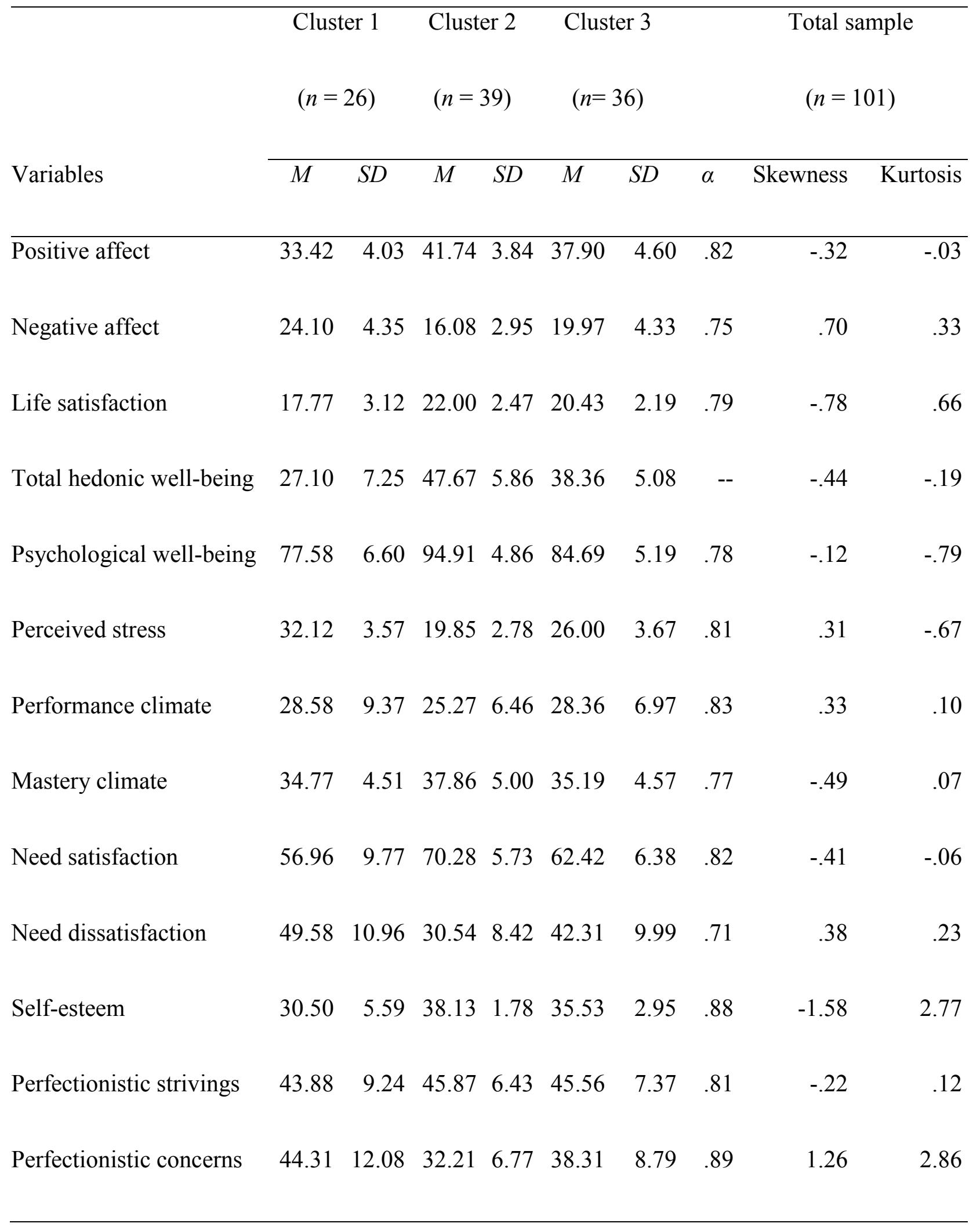


Table 2

Classification Results and Cross-Validation of Frequencies and Percent of Correctly

Classified Cases in Cluster 1 and 2

Predicted group

membership

\begin{tabular}{llll} 
Models & Cluster & Group 1 & Group 2 \\
\hline Original & Cluster 1 & $22(84.6 \%)$ & $4(15.4 \%)$ \\
& Cluster 2 & $1(2.6 \%)$ & $38(97.4 \%)$ \\
Cross-validated & Cluster 1 & $20(76.9 \%)$ & $6(23.1 \%)$ \\
& Cluster 2 & $2(5.1 \%)$ & $37(94.9 \%)$
\end{tabular}

Note. Independent variables included in models are self-esteem, need dissatisfaction, need satisfaction, perfectionistic concerns and mastery-oriented climate. 